\title{
Clinical and Therapeutic Aspects of Perforated Peptic Ulcer in Joseph Ravoahangy Andrianavalona University Hospital Center
}

\author{
Solonirina Davida Rakotomena, Sedera Arimino*, Medyno Mampiadana Lovasoa, \\ Tianarivelo Rajaonarivony, Hery Nirina Rakoto Ratsimba
}

Faculty of Medicine, University of Antananarivo, Antananarivo, Madagascar

Email address:

sederaarimino02@gmail.com (S. Arimino)

${ }^{*}$ Corresponding author

\section{To cite this article:}

Solonirina Davidà Rakotomena, Sedera Arimino, Médyno Mampiadana Lovasoa, Tianarivelo Rajaonarivony, Hery Nirina Rakoto Ratsimba. Clinical and Therapeutic Aspects of Perforated Peptic Ulcer in Joseph Ravoahangy Andrianavalona University Hospital Center. Science Journal of Clinical Medicine. Vol. 8, No. 6, 2019, pp. 66-71. doi: 10.11648/j.sjcm.20190806.12

Received: December 4, 2019; Accepted: December 20, 2019; Published: January 4, 2020

\begin{abstract}
Despite the introduction of $\mathrm{H} 2$ receptor and proton pump antagonists into the therapeutic arsenal of the Peptic Ulcer Disease, gastric perforation remains the most common surgical emergery for the upper gastrointestinal tract. The present study aims to describe the particularities of the management of Perforated Peptic Ulcer which underwent surgery in the University Hospital Center Joseph Ravoahangy Andrianavalona Antananarivo (CHU-JRA) and to identify its morbidity and mortality factors. This is a retrospective analysis performed over a period of 33 months from January 2017 to September 2019 on Perforated Peptic Ulcer operated in CHU-JRA. Demographic, clinical and therapeutic parameters were studied and analyzed in relation to the morbidity and mortality rate. Altogether 158 patients operated for perforated Gastric or Duodenal Ulcer were included with an age ranging from 16 to 78 years old, a mean age of $39.05 \pm 15.03$ years and a Sex Ratio estimated to 18.75 . Repeated unexplored epigastralgia was noted in $70.89 \%$ of cases and $33.54 \%$ of patients used NSAIDs and/or corticosteroids before the onset of the pain. At admission, 9.4\% of cases were immediately in shock. A laparotomy for exploration and repair was performed for a suspicion of a hollow-organ perforation on a X-ray of an Unprepared Abdomen. Antral perforation predominated in our serie $(75.95 \%)$ and the main repair procedure consisted in a simple surgical suture. To conclude, our stude reflects the difficulty of the management of Peptic Ulcer Disease and its complications in our daily practice. Strenghtening the awareness of the population about the potiential severity of this disease is essential.
\end{abstract}

Keywords: Helicobacter pylori, Peptic Ulcer Disease, Perforation, Peritonitis, Surgery

\section{Introduction}

Peptic or Gastric or Gastro-duodenal Ulcer disease results from an imbalance between the natural defense factors of the gastric mucosa (bicarbonate, blood flow, mucus, cell-junction, apical resistance) and agressive factors (gastric acidity, pepsin, Helicobacter pylori Infection HPI and Non-Steroidal Anti-Inflammatory Drugs NSAID) [1]. Gastric perforation is one of the potentially serious complications if its treatment fails or is inadequate [2]. This perforation occurs in $2 \%$ of patients with Peptic Ulcer Disease. It is the most common upper gastrointestinal surgical emergency [3]. Since the introduction of $\mathrm{H} 2$ receptor antagonists in the 1970s and proton pum therapy in the 1980s, the incidence of PUD has decreased. Despite of that, surgery for perforated peptic ulcers remains significant in both developed or developing countries [4]. In the emergency department in the University Hospital Center Joseph Ravoahangy Andrianavalona Antananarivo (CHU-JRA), gastric perforation, all causes combined, is the most frequent cause of secondary peritonitis $(69.25 \%)$ [5]. So this study aims to describe the particularities of the management of perforated ulcers which underwent emergency surgery in our center, and to identify the predisposing factors to morbidity and mortality in order to contribute to the establishment of an appropriate to our context strategy for the immediate and long-term 
management of this pathology.

\section{Methodology}

This is a retrospective analysis of 158 patients over the age of 16 years old who underwent an emergency laparotomy in CHU-JRA from January 2017 to September 2019, and whose surgical exploration revealed a gastric or duodenal perforation on a Peptic Ulcer Disease. We excluded the perforation caused by traumatism, tumour, ischemic or caustic product ingestion.

Demographic parameters, personal medical and surgical history, clinical condition at admission, intraoperative lesions descriptions, surgical procedure and postoperative outcomes were collected from medical records and analyzed. The Chisquare or Fisher's exact test was used for statistical analysis to assess the importance of the studied parameters on morbidity or mortality in our population, considering that $\mathrm{p}$ value less than 0.05 is statistically significant.

\section{Results}

During 33 months, 158 patients operated for ulcerative gastric perforation were collected. They were aged from 16 to 8 years, with an average of $39.05 \pm 15.03$ years. The Sex Ratio was estimated to 18.75 with 150 males patients (94.94\%) (Figure 1).

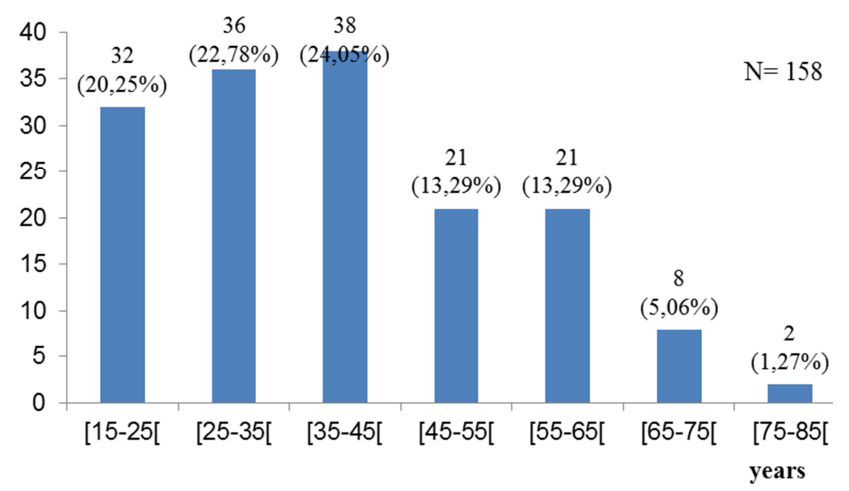

Figure 1. Age distribution.

Table 1 expose the personal histories of our patients, 112 (70.89\%) of them had repeated unexplored epigastric pain, 4 patients $(2.53 \%)$ had been previously treated for PUD. Before the onset of the pain, 53 (33.54\%) of the patients had used NSAIDs and/or corticosteroids. Before surgery, the Helicobacter pylori Infection status was unknown for all the patients.

Table 1. Medical and surgical personal histories of the patients.

\begin{tabular}{lll}
\hline PERSONAL HISTORY & FREQUENCY & PERCENT (\%) \\
\hline Cardio-pulmonary disease & 8 & 5,06 \\
Diabetes & 9 & 5,70 \\
Concomitant pathology & 18 & 11,39 \\
Epigastralgy & 112 & 70,89 \\
NSAIDs and/or corticoids use & 53 & 33,54 \\
Tabagism & 96 & 60,76 \\
\hline
\end{tabular}

\begin{tabular}{lll}
\hline PERSONAL HISTORY & FREQUENCY & PERCENT (\%) \\
\hline Alcohol Consumption & 76 & 48,10 \\
Decoction use & 25 & 15,82 \\
Proved HPI & 4 & 2,53 \\
Gastrectomy & 2 & 1,27 \\
\hline
\end{tabular}

The patients were preoperatively assessed according to the American Society Anaesthesiologist (ASA) classification (Figure 2), so 106 (67.09\%) patients were classified as ASA 2. All of the patients had epigastric pain, the other clinical signs are detailed in the Table 2. Among them, 14 (9.4\%) presented a state of shock upon their admission, 90 (56.96\%) had abdominal contracture. The X-Ray of their Unprepared Abdomen revealed a free air beneath diaphram (crescent sign) indicating a pneumoperitoneum. An abdominal Computed Tomography was requested in 3 patients $(1.90 \%)$ which revealed a pneumoperitoneum associated with intraabdominal fluid effusion.

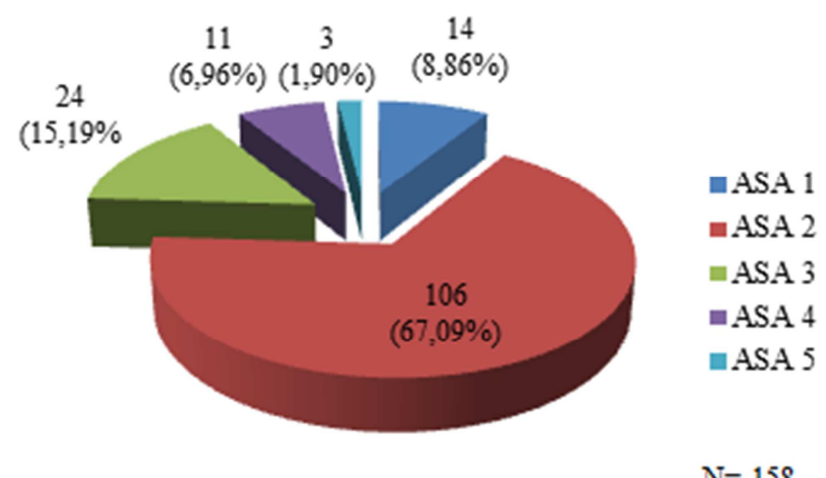

Figure 2. Distribution of the patients according to their ASA classification.

Exploratory laparotomy was performed for all the patients, beyond the first 24 first hours of onset of symptoms for 48 $(30.28 \%)$ of them. Perforated antral ulcers predominated intraoperatively in our serie, estimated to $75.95 \%(n=120)$. (Figure 3). The average perforation size was estimated to $9.38 \pm 10.28 \mathrm{~mm}$ (limits: 2 and $70 \mathrm{~mm}$ ). However, 6 (3.80\%) patients presented a perforation with a diameter over than $30 \mathrm{~mm}$. After reviving the wound and tissue sampling from its edges, a simple surgical suture of the perforation was performed in $130(82.27 \%)$ patients. Two cases of partial gastrectomy associated with a vagotomy were performed before a perforation of more than $70 \mathrm{~mm}$ (Figure 4).

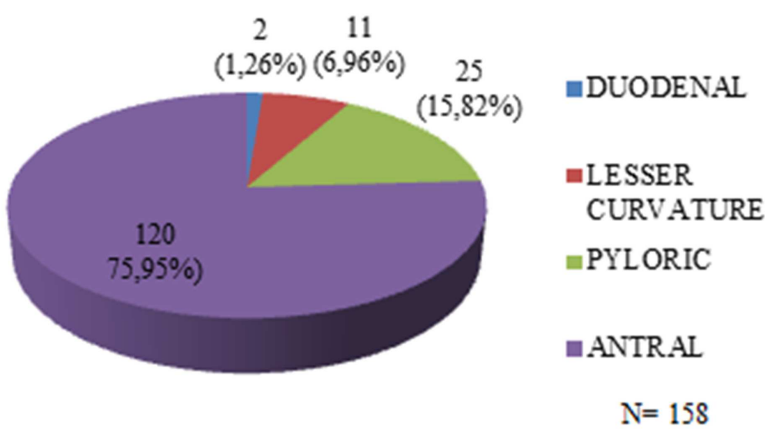

Figure 3. Distribution of the patients according to the perforation site. 


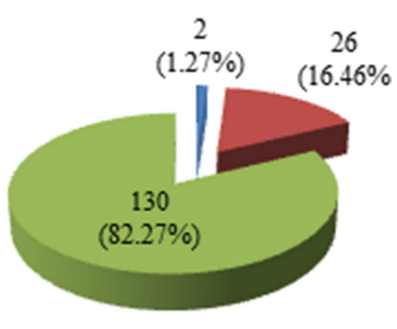
- Partial gastrectomy+ vagotomy
- Simple suture + omental patch
= Simple suture

\section{$\mathrm{N}=158$}

Figure 4. Distribution of the patients according to the surgical technique performed.

The surgical outcomes were simple for 89 (56.33\%) patients, postoperative complications were dominated by hydroelectrolytic disorders (41 patients; $25.95 \%$ ), anemia (35 patients; $22.15 \%$ ) and septic shock (20 patients; $12.66 \%$ ). There had been 15 cases $(9.49 \%)$ of death including 12 $(7.59 \%)$ in the first 24 hours after surgery (Table 2).

Table 2. Postoperative outcomes

\begin{tabular}{lll}
\hline SURGICAL OUTCOMES & FREQUENCY & PERCENT \\
\hline SIMPLES & 82 & $51,90 \%$ \\
COMPLICATIONS & 76 & $48,10 \%$ \\
Hydroelectrolytic troubles & 41 & $25,95 \%$ \\
Anemia & 35 & $22,15 \%$ \\
Septic shock & 20 & $12,66 \%$ \\
Renal failure & 10 & $6,33 \%$ \\
Surgical Site Infection & 9 & $5,70 \%$ \\
Pneumopathy & 8 & $5,06 \%$ \\
Thrombocytosis & 6 & $3,80 \%$ \\
\hline
\end{tabular}

\begin{tabular}{lll}
\hline SURGICAL OUTCOMES & FREQUENCY & PERCENT \\
\hline Urinary infection & 4 & $2,53 \%$ \\
DEATH & 15 & $9,49 \%$ \\
\hline
\end{tabular}

The post-operative management modalities are summarized in Table 3. The average duration of postoperative fasting was $5.41 \pm 1.02$ days, $52(32.91 \%)$ patients received an high in protein parenteral nutrition. Proton pomp was routinely administered via intravenous route during the immediate postoperative period followed by an oral route when liquid intake is authorized. The average lenght of hospitalization was $7.15 \pm 2.67$ days. An Upper GastroIntestinal Endoscopy was systematically requested for each patient aroud the fifth post-operative week. It was performed in 57 patients $(36.08 \%)$ with 52 satisfactory results $(32.91 \%)$.

Table 3. Post-operative management modalities.

\begin{tabular}{llll}
\hline & $\begin{array}{l}\text { Minimum } \\
\text { (day) }\end{array}$ & $\begin{array}{l}\text { Maximum } \\
\text { (day) }\end{array}$ & $\begin{array}{l}\text { Average } \\
\text { (day) }\end{array}$ \\
\hline Mobilization & 1 & 4 & $1,53 \pm 0,96$ \\
Fasting & 4 & 8 & $5,41 \pm 1,02$ \\
Naso-gastric tube ablation & 2 & 9 & $4,81 \pm 1,00$ \\
Abdominal drain ablation & 0 & 8 & $4,39 \pm 1,13$ \\
\hline
\end{tabular}

Table 4 presents the influence of various demographic, clinical and therapeutic parameters on the morbidity and mortality of our patients. After analysis, the delay in treatment (more than 24 hours after the onset of the symptoms) and the state of shock preoperatively seemed to constitute the main prognostic factors in our study population.

Table 4. Demographic, diagnostic and therapeutic particularities.

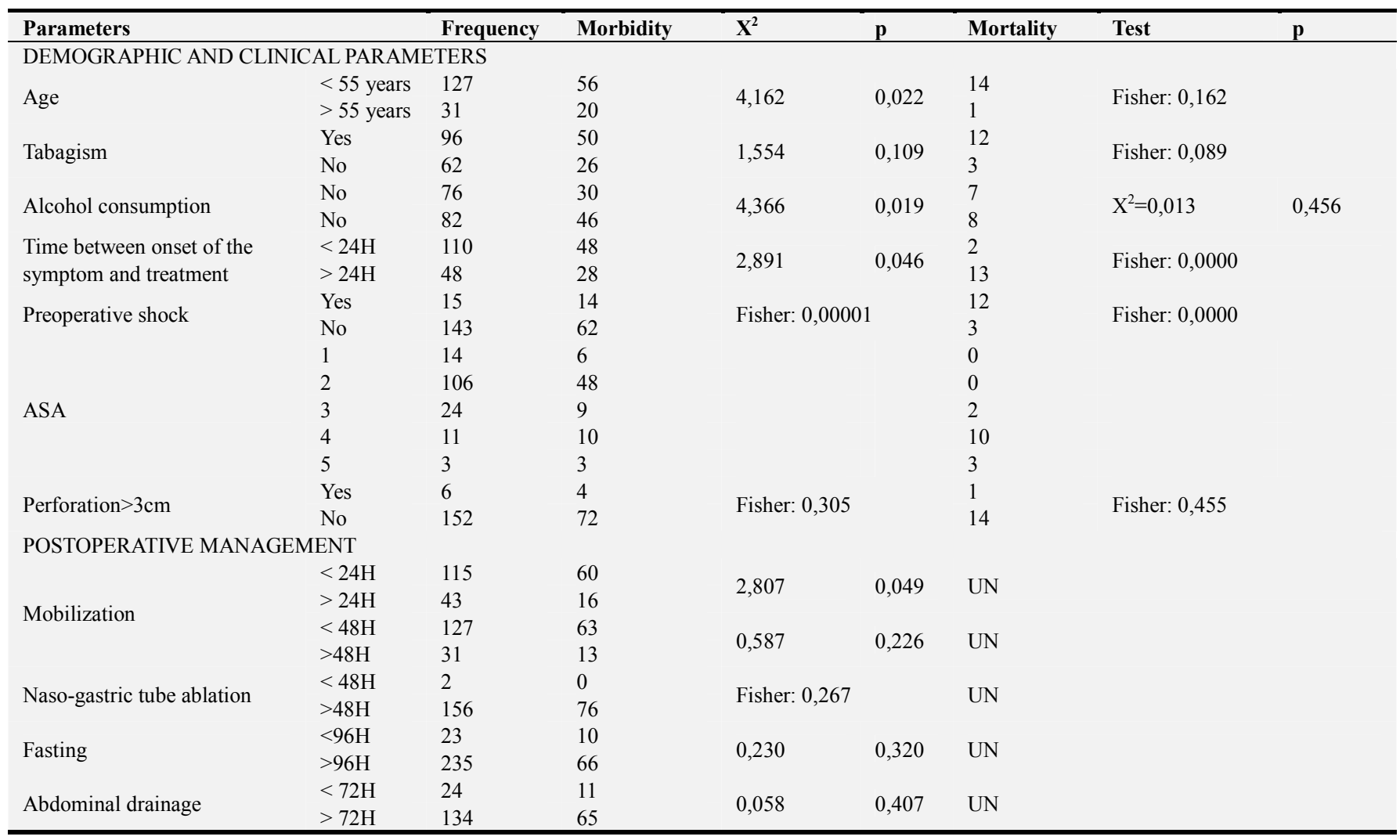

UN: Unanalyzed. 


\section{Discussions}

Peptic Ulcer Disease is the most common cause of gastric perforation [6]. Over past decades, a downward trend of the incidence of ulcerative stomach perforation has been observed, particularly in younger patients, in contrast with its increase in older patients [7]. In our serie, $127(80.38 \%)$ patients were under 55 years old. The consumption rate of NSAIDs or corticosteroid among our patients was estimated to $33.54 \%$. This could be attributed to self-medication in our context. The importance of the illegal sale of drugs by unauthorized sellers remains a public health problem in our country.

In addition to Helicobacter pylori Infection which is an infectious agent found in 75 to $85 \%$ of patients with PUD [4], increased use of NSAIDs [2, 8, 9] multidrug therapy in the treatment of high blood pressure and concomitant diseases such as coronary heart disease, diabete, chronic obstructive pulmonary disease and renal failure play a key role in the physiopathology of the perforation in the elderly subjects [10].

Men are more affected by PUD perforation than women [2, $5,11]$. In our study, the Sex Ratio was estimated to 18.75 . This net predominance may be related to behaviours sush as smoking, alcohol consumption more frequent among men, especially among young adults [10, 12]. In addition, according to some authors, medicinal plants also constitute an important risk factors for PUD and its complications [2, 4]. In our country, decoction, an ancestral Malagasy culture using plants without medical supervision, remains a threat because of the scarcity of studies focusing on its harms.

Upon admission, the patients generally describe a sudden and severe epigastralgia, initially localized then rapidly become widespread. Sometimes it is associated with symptoms of dizziness or syncope secondary to hypotension due to blood loss or Systemic Inflammatory Response Syndrome (SIRS) [13, 14]. However, the clinical characteristics of ulcerative gastric perforation in elderly patients are different and less specific, sometimes atypical or less intense compared to the younger $[15,17]$.

In any case, the diagnosis of ulcerative perforation of the stomach should be made quickly and appropriately. In his experiment, Hemmer argues that a simple chest X-ray was fast and useful to guide the diagnosis of perforated gastric ulcer revealing an image of pneumoperitoneum as a crescent gas under diaphragm [4]. In our series, the discovery of pneumoperitoneum on radiological images which led us to suspect an hollow organ perforation, was sufficient to decide for an urgent surgery. Furthermore, abdominal ultrasound and Computed Tomography with contrast injection can also help to guide diagnosis by the presence of intra-abdominal fluid effusion but have the disadvantage of being more expensive and depend on the operator In the case of a large gastric ulcer perforation, CT has its advantage because, in addition to the presence of pneumoperitoneum, it could specify the site of perforation by the concentration of extraluminal air bubbles in immediate proximity or by revealing a thickening of the focal wall of the stomach and its discontinuity [18]. Extravasation of the oral contrast on CT gives the diagnosis of perforation with a low sensitivity, between $19 \%$ and $42 \%$ with the risk of delaying the surgical procedure [19].

Perforated gastric ulcer is potentially a complicated surgical emergency. An early and appropriate management is essential to avoid additional complications, including unnecessary gastrectomy [20]. Associated complications may include hemorrhage with its effects, progressive alteration of the patient's general state due to SIRS, or even sepsis $[15,18]$

The choice of approach in the management of gastric perforation, regardless of its size, depends on the infrastructure of the Center and the operator. Indeed, laparoscopy is now increasingly used, even before a giant gastric ulcers [18]. Many authors reported its safety and efficiency in this case [21-23]. Due to our obsolete infrastructure, the traditional approach is the only available for our surgical team.

Intraoperatively, the topography of the ulcerous perforation in the stomach are anatomically classified into: cardial, fundic, antral and pyloric [2]. According to Leeman, gastric perforation is mainly located on the distal part of the stomach, specifically at the last third [20]. Hemmer confirms this by finding $82.5 \%$ of his cases in the antral region and the first part of the duodenum. The same author also points out that the perforations are more frequent in the stomach than in the duodenum $(58.6 \%$ vs. $41.6 \%)$ [4]. Our study founds $75.95 \%$ antral perforation in all locations combined with $6.96 \%$ concerning the small curvature of the stomach. In addition, precising if the perforation is located on the anterior or posterior face of the stomach may be relevant because the unavoidable opening of the omental bursa in the event of a posterior case, may have an impact on the surgical time and morbidity of the pathology.

The surgical strategy also depends on the perforation diameter [12]. The upper limit of the perforation size varies according to the series. Agustin noted gastric perforations ranging from 1 to $5 \mathrm{~cm} \mathrm{[2].} \mathrm{In} \mathrm{the} \mathrm{present} \mathrm{study,} \mathrm{perforations}$ measured from $2 \mathrm{~mm}$ to $7 \mathrm{~cm}$, giant gastric ulcers were few (4/158 cases). According to the literature, if laparotomy is performed with the discovery of a perforated gastric ulcer, the appropriate traditional approach is a simple suture combined with local excision of the ulcer for reviving and biopsy, and then reconstruction [20]. This therapeutic strategy was also our choice in $82.82 \%$ of cases. In recent years, the simple suture of perforated peptic ulcer disease by open or laparoscopic surgery has been increasingly recommended as the optimal surgical treatment [24]. According to Chandra, in the case of a small gastric perforation, the omental patch on the suture is an option [12]. But in the case of a simple duodenal ulcer, making an omental patch above the suture would be the optimal procedure [20]. On another hand, gastric resection is usually reserved for giant ulcer perforations [24]. Indeed, a perforated giant gastric ulcer (diameter $>3 \mathrm{~cm}$ ), even rare 
$(<2 \%)$, presents a serious surgical management challenges, especially if the patient suffers from severe comorbidity or if there is a delay in diagnosis. Turner recommended gastric resection for large and pre-pyloric ulcers [25]. Other authors prescribe an additional omental sealing. There are other surgical options such as the free jejunal pedicle flap, partition wall construction and Finney's pyloroplasty, rarely used [18]. Nivatongs recommends for the patients using NSAIDs and for the Helicobacter pylori infection, the combination of acid-reducing gastric surgery such as a truncular or a selective vagotomy [12].

In addition, knowing the status of Helibacter pylori infection status is difficult around the period of surgery, its eradication should be systematically carried out. Thus, Leeman recommends postoperative gastroscopy for follow-up as soon as the patient's condition permits it [20]. In our practice, this examination is requested around the 5th post-operative week or one week after the end of the triple therapy for eradication of Helicobacter pylori infection, in order to evaluate its effectiveness, but also to verify the healing and absence of recurrence of ulcers, and to exclude malignancy. But the participation of our study population in this review was limited to $36.08 \%$, probably for financial reasons. However, we found $32.91 \%$ of healing without recurrence in the short term.

Finally, perforation remains a frequent and fatal surgical complication despite the availability of effective medical treatment for Peptic Ulcer Disease [7, 12]. Its management needs multidisciplinary team because aggressive resuscitation must be combined with surgery to correct tachycardia and hypotension caused by sepsis [4].

Some therapeutic procedures are currently controversial if a few decades ago they were still a habit, or even a tradition, including prophylactic drainage of the abdomen. The metaanalysis carried out by Messager had found any argument of the drainage after a partial or total gastrectomy on the postoperative morbidity and mortality, or on the diagnostic and management of a fistula, but with a low level of evidence [26]. In our study, it was systematically performed in the presence of intraperitoneal infection caused by the gastric contents discharged in the abdomen and to early detect complications such as digestive fistula, to avoid collections, and to reduce postoperative morbidity. However, we noted an average time to remove the drain of 4.39 days \pm 1.13 days and the absence of significant impact on the morbidity of our patients. Also in this sense, we opted for gastric sampling with an average duration of 4.81 days \pm 1.00 . Our results showed that this procedure does not have a significant impact on the morbidity. Slim had concluded that this procedure was unnecessary in the case of bariatric gastric surgery, regardless of the type of gastrectomy performed [27]. Subsequently, in the Hemmer series, the average time to resumption of feeding was 2.95 days (range: 0-10). Ours was much longer, $5.41 \pm 1.02$ (4 to 8 days), but we had not noted a statistically significant influence on the morbidity of our patients [4].

Peptic Ulcer Disease perforation is a pathological entity associated with high morbidity and mortality $[12,29]$. The complications are numerous and serious: anemia, pneumopathy, cardiopulmonary insufficiency and multiorgan failure [4]. According to Chandra, following a simple closure, the mortality rate of ulcerative gastric perforation remains quite high $(24.1 \%)$ with a morbidity rate equal to $27.5 \%$. This author indicated that this morbidity rate, and those of simple closure associated with acid-reduction surgery $(37.5 \%)$ and gastric resection $(35.2 \%)$ were not significantly different [12]. Møller reported a higher mortality rate $(27 \%)$ [28]. On the other hand, the 30-day mortality rate reported in the literature ranges from 4 to $31 \%$ [4]. In our series, we noted an early mortality of $7.59 \%$ and an overall mortality of $9.49 \%$, which are quite acceptable compared to the data in the literature.

Finally, the delay between the onset of symptoms and the treatment, the age, the presence or not of a shock at admission and the status based on ASA are factors to consider when predicting complications and mortality. A delay of more than 24 hours would increase lethality by 7 to 8 times, and the complication rate by three times more [3].

\section{Conclusion}

The results of our study reflect the difficulty of managing ulcerative diseases and their complications in our daily practice. This difficulty is compounded by the negligence of the patients to consult, by the non-adherence in the treatment, by selfmedication. These attitudes lead to a progressive increase of the incidence of perforated gastric ulcer, to worsen the prognosis and promote its occurrence in young subjects. Raising awareness among our population about the potential severity of this disease is essential. Finally, for the management of gastric or duodenal ulcer perforations, multidisciplinary collaboration is a key factor in patient outcome.

\section{References}

[1] Laine L, Takeuchi K, Tarnawski A. Gastric mucosal defense and cytoprotection: bench to bedside. Gastroenterology 2008; 135 (1): 41-60.

[2] AGUSTIN, Esthiningrum Dewi; PUTRO, Mamiek Dwi; PURBAYU, Herry. Characteristic of Patients with Gastric Perforation due to Peptic Ulcer in Dr. Soetomo General Hospital Surabaya in the Period of January - December 2016. JBN (Jurnal Bedah Nasional), [S. I.], v. 3, n. 2, p. 45-49, sep. 2019.

[3] Gulzar JS, Paruthy SB, Arya SV. Improving outcome in perforated peptic ulcer emergency surgery by Boey scoring. Int Surg J 2016; 3 (4): 2120-2128.

[4] Hemmer PH, de Schipper JS, van Etten B, Pierie JP, Bonenkamp JJ, de Graaf PW, Karsten TM. Results of surgery for perforated gastroduodenal ulcers in a Dutch population. Dig Surg 2011; 28: 360-366.

[5] Rakotomavo FA, Riel AM, Rakotoarison RCN, Randrianambinina H, Randrianambinina T, Randriamiarana MJ. Péritonite aigue: aspects épidémio-clinique et étiologique dans un des urgences chirurgicales malgache. A propos de 60 cas. Journal Africain d'Hépato-Gastroentérologie 2012; 6; 1: 33-67. 
[6] Hata T, Sakata N, Kudoh K, Shibata C, Unno M. The best surgical approach for perforated gastric cancer: one-stage vs. two-stage gastrectomy. Gastric Cancer 2014; 17 (3): 578-587.

[7] Bardhan KD, Williamson M, Royston C, Lyon C. Admission rates for peptic ulcer in the Trent region, UK, 1972-2000. Changing pattern, a changing disease ? Dig Liver Dis 2004; 36 (9): 577-588.

[8] Rajesh TR, Santhosh TV. Non-traumatic gastric perforations. J. Evid. Based Med. Healthc 2019; 6 (6): 327-330.

[9] Janik J, Chwirot P. Perforated peptic ulcer time trends and patterns over 20 years. Med Sci Monit 2000; 6: 369-372.

[10] Gökakin AK, Atabey M, Koyuncu A, Topcu O. Peptic Ulcer Perforation in Elderly: 10 years' experience of a single institution. International Journal of Gerontology. 2016; 10: 198-201.

[11] Lohsiriwat V, Prapasrivorakul S, Lohsiriwat D. Perforated peptic ulcer: clinical presentation, surgical outcomes, and the accuracy of the Boey scoring system in predicting postoperative morbidity and mortality. World J Surg 2009; 33 (1): 80-85.

[12] Chandra SS, Siva Kumar S. Definitive or conservative surgery for perforated gastric ulcer ? - An unresolved problem. International Journal of Surgery 2009; 7: 136-139.

[13] Lau JY, Sung J, Hill C, Henderson C, Howden CW, Metz DC. Systematic review of the epidemiology of complicated peptic ulcer disease: incidence, recurrence, risk factors and mortality. Digestion 2011; 84 (2): 102-113.

[14] Krobot K, Yin D, Zhang Q, Sen S, Altendorf-Hofmann A, Scheele J, Sendt W. Effect of inappropriate initial empiric antibiotic therapy on outcome of patients with communityacquired intra-abdominal infections requiring surgery. Eur $\mathrm{J}$ Clin Microbio Infect Dis 2004; 23 (9): 682-7.

[15] Tran B-K, Groebli Y, Desbaillet YE, Della Santa V. Abdomen aigu chez la personne âgée aux urgences. Rev Med Suisse 2012; 8: 1548-1552.

[16] Chang C, Wang SS. Acute abdominal pain in the elderly. Int J Gerontol 2007; 1: 77-82.

[17] Christensen S, Riis A, Nørgaard M, Sørensen HT, Thomsen RW. Short-term mortality after perforated or bleeding peptic ulcer among elderly patients: a population-based cohort study. BMC Geriatr 2007; 7: 8

[18] Vashistha N, Singhal D, Makkar G, Chakravarty S, Raj V.
Management of giant gastric ulcer perforation: report of a case and review of the literature. Case Reports in Surgery 2016; doi: $10.1155 / 2016 / 468198,3$ pages.

[19] Hainaux B, Agneessens E, Bertinotti R, De Maertelaer V, Rubesova E, Moschopoulos C. Accuracy of MDCT in predicting site of gastrointestinal tract perforation. American Journal of Roentgenology, 2006; 187 (5): 1179-1183.

[20] Leeman MF, Skouras C, Paterson-Brown S. The management of perforated gastric ulcers. International Journal of Surgery. 2013; 11: 322-324.

[21] Bertleff MJ, Halm JA, Bemelman WA, Van Der Ham AC, Van Der Harst E, Oei HI, Smulders JF, Steyerberg EW, Lange JF. Randomized clinical trial of laparoscopic versus open repair of the perforated peptic ulcer: the LAMA Trial. World J Surg 2009; 33: 1368-1373.

[22] Lunevicius R, Morkevicius M: Systematic review comparing laparoscopic and open repair for perforated peptic ulcer. Br J Surg 2005; 92: 1195-1207.

[23] Siu WT, Leong HT, Law BK, Chau CH, Li AC, Fung KH, Tai YP, Li MK. Laparoscopic repair for perforated peptic ulcer: a randomized controlled trial. Ann Surg 2002; 235: 313-319.

[24] Kocer B, Surmeli S, Solak C, Unal B, Bozkurt B, Yildririm O, Dolapci M, Cengiz O. Factors affecting mortality and morbidity in patients with peptic ulcer perforation. Journal of Gastroenterology and Hepatology 2007; 22: 565-570.

[25] Turner WW Jr, Thompson WM Jr, Thal ER. Perforated gastric ulcers. A plea for management by simple closures. Arch Surg 1988; 123 (8): 960-964.

[26] Messager M, Sabbagh C, Denost Q, Regimbeau JM, Laurent C, Rullier E, Sa Cunha A, Mariette C. Quel intérêt au drainage abdominal prophylactique en chirurgie digestive élective majeure ? Journal de Chirurgie Viscérale 2015; 152: 316-326.

[27] Slim K. Fast-tracking en postopératoire: chasse aux sondes, marche et alimentation précoce. Anesth Reanim 2015; 1: 429434.

[28] Møller MH, Shah K, Bendix J, Jensen AG, ZimmermannNielsen E, Adamsen S, Møller A. Risk factors in patients surgically treated for peptic ulcer perforation. Scand J Gastroenterol 2009; 44: 145-152.

[29] Taş İ, Ulger BV, Önder A, Murat Kapan M, Zübeyir Bozdağ Z. Risk factors influencing morbidity and mortality in perforated peptic ulcer disease. Ulus Cerrahi Derg 2014; 31: 20-25. 